\title{
Methodology of Indicative Analysis to Determine the Municipal Units for Implementation of the Energy-Saving Strategy
}

\author{
Valery STENNIKOV ${ }^{1}$, Ivan POSTNIKOV ${ }^{2 *}$, Olga EDELEVA ${ }^{3}$ \\ ${ }^{1-3}$ Melentiev Energy Systems Institute of Siberian Branch of the Russian \\ Academy of Science (ESI SB RAS), Irkutsk, Russia
}

\begin{abstract}
This paper proposes a two-stage approach to choose the priority municipal units for implementing required energy efficiency measures in a district heating system. On the first stage the existing state of district heating system of Irkutsk region (Eastern Siberia) was analysed. On the second stage the choice of municipal units is considered as the Multiple Criteria Decision Analysis (MCDA) problem. The authors selected the most valuable criteria such as tariffs, subsidies and etc. that are rather sensitive for consumers and budget. The Technique for Order Preference by Similarity to Ideal Solution (TOPSIS) was applied to identify the priority municipal units for implementing energy efficiency measures.
\end{abstract}

Keywords - District heating systems; energy efficiency measures; energy-saving strategy; heat tariff; indicative analysis; multiple criteria analysis; municipal units; subsidization indicator

\begin{tabular}{|lll|}
\hline \multicolumn{2}{|c|}{ Nomenclature } & \\
$i$ & index of municipal unit $i=1,2, \ldots, m$ & - \\
$j$ & index of indicator $j=1,2, \ldots, n$ & - \\
$\mathbf{B}$ & decision matrix & - \\
$k_{i j}$ & value of the indicator & - \\
$\mathbf{C}$ & normalized decision matrix & - \\
$c_{i j}$ & element of matrix $\mathbf{C}$ & - \\
$\mathbf{\Lambda}$ & weighted normalized decision matrix & - \\
$\lambda_{i j}$ & element of matrix $\boldsymbol{\Lambda}$ & - \\
$\mu_{j}$ & weight value of the indicator $j, \sum_{j=1}^{n} \mu_{j}=1$ & - \\
$B^{+}$ & positive ideal alternative & - \\
$B^{-}$ & negative ideal alternative & - \\
$Y_{U}$ & set of maximized indicators & - \\
$Y_{Z}$ & set of minimized indicators & - \\
$h_{i}^{+}$ & Euclidean distance from $B_{i}$ to the positive ideal alternative \\
$h_{i}^{-}$ & Euclidean distance from $B_{i}$ to the negative-ideal ideal alternative \\
$F_{i}$ & relative distance to the ideal alternative & \\
\hline
\end{tabular}

* Corresponding author.

E-mail address: postnikov@isem.irk.ru

(C)2020 Valery Stennikov, Ivan Postnikov, Olga Edeleva.

This is an open access article licensed under the Creative Commons Attribution License (http://creativecommons.org/ 


\section{INTRODUCTION}

Currently, the theory and practice of design and operation control of the efficient district heating systems (DHS) are actively developing. These systems are of high socio-economic importance in the countries located in the geograhical zones with a cold climate. One of the key conception of DHS development is the transition to the 4th generation of DHS (4GDH systems) [1]-[4]. This technological conception involves a number of both technical and organizational solutions which provide a new level of efficiency of the thermal energy production, distribution and consumption. At the same time, the upgrade of existing systems up to $4 \mathrm{GDH}$ implies the solution of many new fundamental methodological and practical problems.

The key features of the 4GDH systems are: use of low-temperature heat energy (lowtemperature schedule) in order to reduce losses; recovery of thermal energy from lowtemperature sources; use of renewable energy sources (RES) and their integration with other energy suplly systems (power, natural gas, etc.); intelligent (with the high level of automatation) methods of system control [4]. Also many authors pay attention to the carbon dioxide emissions reduction, for example [5]-[7], which generally depends on the RES share increase [8].

One of the most important problems of effective modernization of Russian DHS is the energy-saving policy making [9]. The potential for thermal energy energy-saving in Russian DHS functioning in the different MU like cities, towns is quite high (from 15 to $25 \%$ of the total thermal energy production).

The implementation of an energy-saving policy leads to transformation of the organizational structure in the DHS management. Many authors pay attention to the need of special training of manufacturers, consumers and municipal authorities before the technical re-equipment of existing systems [10], [11]. Some methodological approaches are developed for municipal energy planning: for example, an approach is proposed in [12] for ranking of municipal energy decisions. Special models assess the effectiveness of various scenarios of the DHS development [13]-[15]. Also, it is noted that an comprehensive approach is needed to evaluate the profit of new projects in the energy sector. The authors of [16] proposed an approach for energy planning using the weight coefficients. The role of energy experts in this process is especially highlighted. Another example of an indicative analysis that used for municipal waste management is presented in [17].

In this paper, a methodology for the selection of priority municipal units (MU) for the implementation of the thermal energy-saving strategy is proposed. This task was established by the Government of the Irkutsk Region in 2010 to realize the federal energy-saving program [18]. Usually, the decision making begins with the definition of priority energy-saving measures [19]-[21]. In this case, we at first determined the MUs which DHS's state is the worst and they as soon as possible required the energy-saving policy implementation.

\section{Methodology}

The proposed methodology involves two main stages: problem structuring; analysis [22]. Each stage, in its turn, consists of some steps shown in Fig. 1. The first stage aims to understand the decision context and to structure the problem. It begins from structuring the goals of energy-saving development. Then the data analysis phase creates a supportive database. The available data about the existing subsidy, efficiency of boiler capacity use, tariffs, MU statistical data atc. 
Average hot water tariff has been collected and analysed for performing two next steps: possible alternative definition and formulation of indicators to assess how each alternative contributes to achieving the goals.

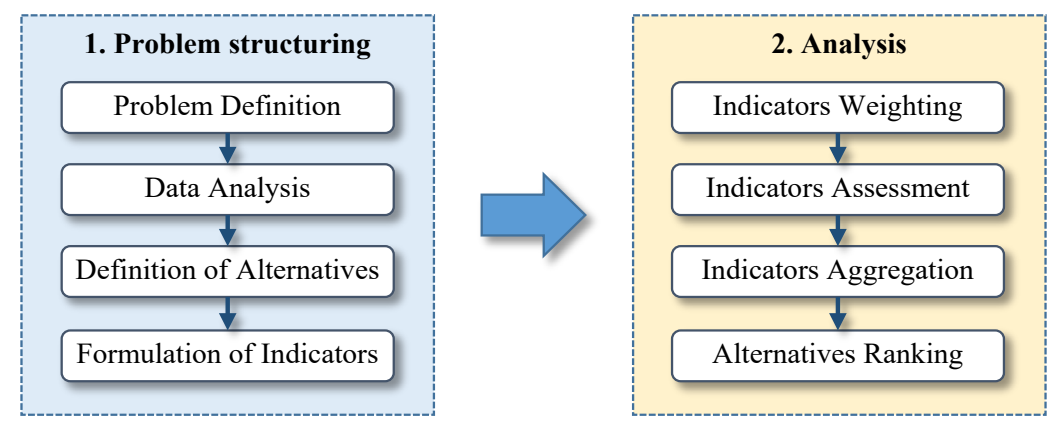

Fig. 1. Conceptual scheme of proposed methodology.

The second stage is the actual analysis, consisting of indicators weighting, assessment, aggregation and alternatives ranking steps.

Indicators weighting step assigns a value to each indicator that indicates its relative importance with respect to the other considered indicators. The indicators can be of different importance or not but the sum of their weights must be equal to 1 .

Indicators assessment is the quantification of the impact of each alternative against each indicator defined in the first stage. The result is a matrix providing information about the effects of each alternative on each indicator. Indicators aggregation refers to the application of a rule to process the output of indicators assessment and weighting steps and evaluate the total performance of each alternative. Various MCDA approaches apply different decision rules to aggregate the performance of the alternatives across indicators. Last, outranking the alternatives is one of several methods to summarize the results of the indicators aggregation and to distinguish the best ones.

The choice of priority MU for implementing required energy efficiency measures and energy efficiency is MCDA problem. If you solve this problem by expert means, it may turn out that each expert will have his own preferences for choosing. In turn, the methods of MCDA help decisionmakers evaluate a set of objects to choose the most preferable one, classify or rank a set of objects according to several indicators in accordance with given preferences. In this work, the MU are considered as objects, so the indicators are criteria of their energy efficiency.

Today, there are a number of MCDA methods, each of which has a certain set of advantages [23], [24]. The TOPSIS method requires only a minimal number of inputs from the user and its output is easy to understand [25], [26].

The purpose of this practical study is to select a list of MUs, i.e. definition of not one, but a set of the best MU. In TOPSIS, the values of the indicators are first normalized, according to which the position of the alternative under investigation is determined relative to the best and worst variants, as well as in relation to each other, then the calculated distances between them are used to classify alternatives.

The TOPSIS method consists of five steps [27]:

1. Calculate the normalized decision matrix $\mathbf{B}$.

The decision matrix $\mathbf{B}$ is filled with the values of the $k_{i j}$ indicators, and then a normalized matrix $\mathbf{C}$ is built on the basis of the matrix $\mathbf{B}$. The element $C_{i j}$ of matrix $\mathbf{C}$ is defined as follows: 


$$
c_{i j}=\frac{k_{i j}}{\sqrt{\sum_{i=1}^{m} k_{i j}^{2}}} .
$$

2. Determine the weighted normalized decision matrix $\Lambda$ The weighted normalized decision matrix $\Lambda$ based on matrix $\mathbf{C}$. The weighted normalized value $\lambda_{i j}$ is defined as follows:

$$
\lambda_{i j}=\mu_{j} c_{i j} .
$$

3. Determine the ideal and negative ideal alternative. The ideal alternative and the negative ideal alternative denoted as $B^{+}$and $B^{-}$respectively, are defined as:

$$
\begin{aligned}
& B^{+}=\left\{\left(\lambda_{1}^{+}, \lambda_{2}^{+}, \ldots, \lambda_{n}^{+}\right)\right\}=\left\{\left(\max _{i} \lambda_{i j} \mid j \in Y_{U}\right),\left(\min _{i} \lambda_{i j} \mid j \in Y_{Z}\right)\right\}, \\
& B^{-}=\left\{\left(\lambda_{1}^{-}, \lambda_{2}^{-}, \ldots, \lambda_{n}^{-}\right)\right\}=\left\{\left(\min _{i} \lambda_{i j} \mid j \in Y_{U}\right),\left(\max _{i} \lambda_{i j} \mid j \in Y_{Z}\right)\right\},
\end{aligned}
$$

where, $Y_{U}$ is the set of maximized indicators, $Y_{Z}$ is the set of minimized indicators.

4. Calculate as well as the distance between alternative. The Euclidean distance from $B_{i}$ to the ideal and negative-ideal alternatives is calculated as follows:

$$
\begin{aligned}
& h_{i}^{+}=\sqrt{\sum_{j=1}^{n}\left(\lambda_{i j}-\lambda_{j}^{+}\right)^{2}}, \\
& h_{i}^{-}=\sqrt{\sum_{j=1}^{n}\left(\lambda_{i j}-\lambda_{j}^{-}\right)^{2}},
\end{aligned}
$$

5. Calculate the relative distance to the ideal alternative. Calculate the relative distance $F_{i}$ to the ideal alternative, defined as:

$$
F_{i}=h_{i}^{-} /\left(h_{i}^{+}+h_{i}^{-}\right) .
$$

The calculated values $F_{i}$ are in the range $[0 ; 1]$ and they can be ordered in descending order. The object $B_{i}$ with the highest value $F_{i}$ is selected as the most preferred.

\section{Case Study}

Cost of heat to consumers is one of the most important indicators of assessing the energy situation that impacts heat tariffs. Many boilers of MU have high operating costs caused by excessive consumption of fuel due to low efficiency and by high fuel costs, primarily in the northern regions. This results in high heat tariffs for population (Fig. 2). Difference between economically feasible (corresponding to production cost) and valid heat tariffs in many areas is subsidized, therefore, it is difficult to get a realistic idea of the heat supply at present day tariffs. However, despite this fact, they give a certain idea on motives of the directions of modernizing the municipal DHS.

Subsidization indicators for preparation of municipal infrastructure facilities for heating season divided by the value of heat consumed by population and utilities in MU of Irkutsk region are shown in Fig. 3.

Specific MU subsidization indicator allows more certain identification (as compared to tariffs regulated by subsidies) of the priority MU that need urgent solution of DHS problems [28], [29]. 


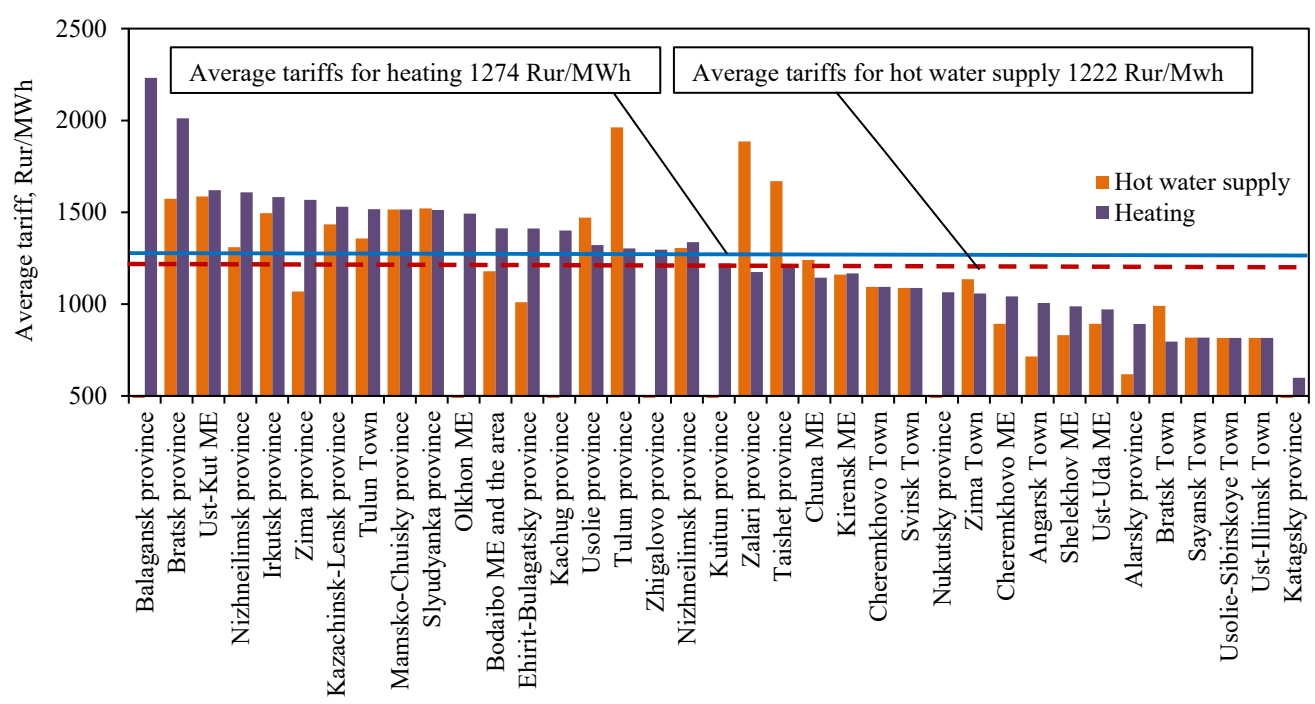

Fig. 2. Heat and hot water tariffs established by regulatory organizations for population of MU in the Irkutsk region.

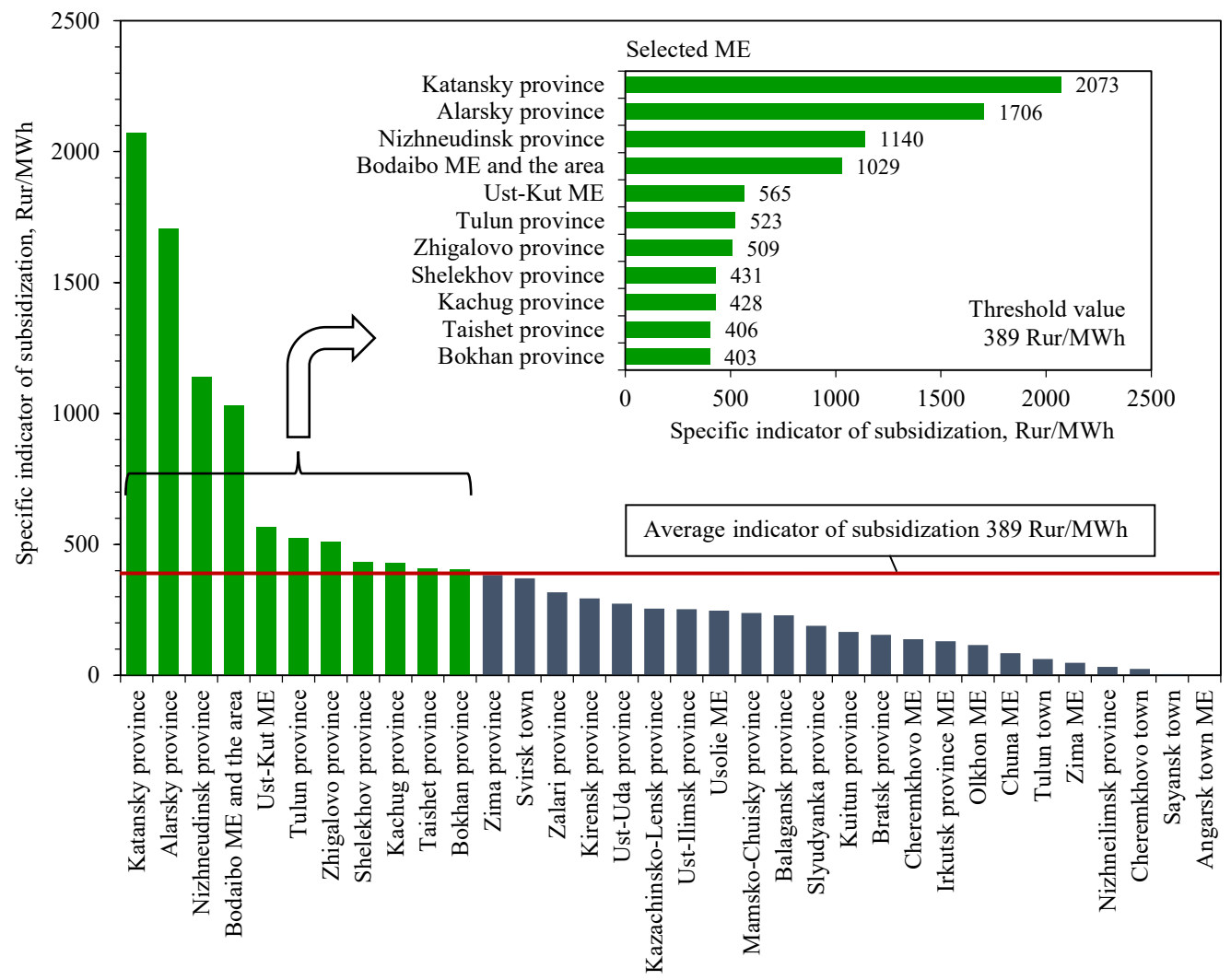

Fig. 3. Indicator of volumes of state subsidies of MU in the Irkutsk region. 
$2020 / 24$

The efficiency of boiler capacity use is one of indicators characterizing the condition and efficiency of operation of the main facilities of DHS (Fig. 4). The reserve of $25 \%$ is sufficient for ensuring normal operation (the solid line in Fig. 4). The collected Irkutsk region MU data is shown in the Table 1.

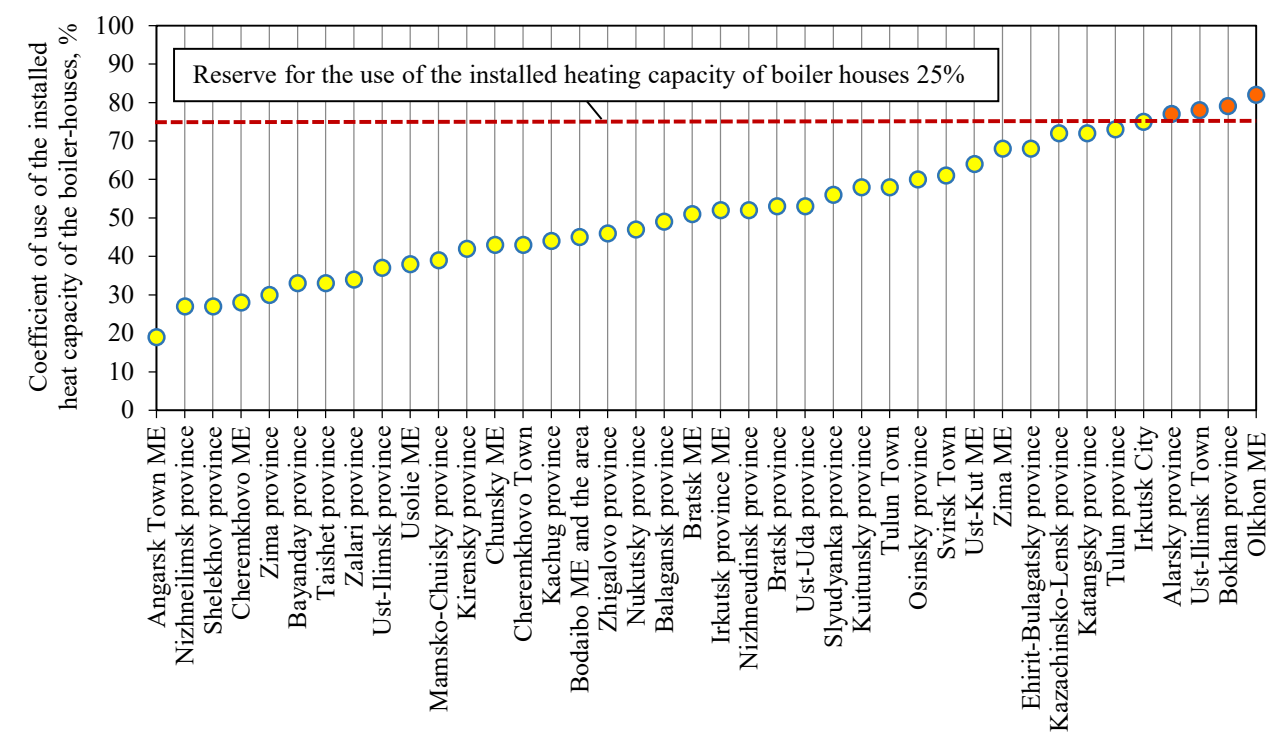

Fig. 4. Efficiency of boiler capacity use in MU of the Irkutsk region.

TABLE 1. INDICATORS FOR AsSESSING THE StATE OF THE HeAt POWER INDUSTRY IN SEVERAL MU OF IRKUTSK REGION

\begin{tabular}{lllll}
\hline \multirow{2}{*}{ Name of MU } & $\begin{array}{l}\text { Subsidization } \\
\text { indicator, } \\
\text { Rur/MWt }\end{array}$ & $\begin{array}{l}\text { Efficiency of boiler } \\
\text { capacity use, } \%\end{array}$ & \multicolumn{2}{c}{$\begin{array}{l}\text { Average tariff, } \\
\text { Rur/MWt }\end{array}$} \\
\cline { 4 - 5 } & 1 & 19 & Hot water & Heat \\
\hline Angarsk Town & 1140 & 27 & 715 & 1007 \\
Nizhneilimsk province & 431 & 27 & 1306 & 1338 \\
Shelekhov province & 138 & 28 & 831 & 988 \\
Cheremkhovo MU & 383 & 30 & 893 & 1042 \\
Zima province & 406 & 33 & 1069 & 1568 \\
Taishet province & 317 & 34 & 1670 & 1208 \\
Zalari province & 252 & 37 & 1886 & 1175 \\
Ust-Ilimsk province & 247 & 38 & 816 & 816 \\
Usolie MU & 238 & 39 & 816 & 816 \\
Mamsko-Chuisky province & 294 & 42 & 1515 & 1515 \\
Kirensk province & 84 & 43 & 1160 & 1167 \\
Chuna MU & 24 & 43 & 1241 & 1144 \\
Cheremkhovo Town & 428 & 44 & 1094 & 1094 \\
Kachug province & & & 0 & 1401 \\
\hline
\end{tabular}




\begin{tabular}{lllll}
\hline Bodaibo MU and the area & 1029 & 45 & 1179 & 1413 \\
Zhigalovo province & 509 & 46 & 0 & 1297 \\
Balagansk province & 230 & 49 & 0 & 2232 \\
Irkutsk province MU & 131 & 52 & 1495 & 1583 \\
Nizhneudinsk province & 32 & 52 & 1306 & 1338 \\
Bratsk province & 155 & 53 & 1574 & 2011 \\
Ust-Uda province & 274 & 53 & 893 & 971 \\
Slyudyanka province & 189 & 56 & 1521 & 1513 \\
Kuitun province & 166 & 58 & 0 & 1222 \\
Tulun Town & 62 & 58 & 1358 & 1517 \\
Sayansk town & 4 & 60 & 818 & 818 \\
Svirsk Town & 370 & 61 & 1088 & 1088 \\
Ust-Kut MU & 565 & 64 & 1587 & 1620 \\
Zima MU & 48 & 68 & 1136 & 1058 \\
Kazachinsko-Lensk province & 255 & 72 & 1434 & 1530 \\
Katangsky province & 2073 & 72 & 0 & 599 \\
Tulun province & 523 & 73 & 1963 & 1303 \\
Alarsky province & 1706 & 77 & 618 & 892 \\
Olkhon MU & 116 & 82 & 0 & 1493 \\
\hline
\end{tabular}

Table 2 shows the weight values of the energy efficiency indicators according to their importance. The subsidization indicator and efficiency of boiler capacity use have equal high values of weights. The value of tariff indicator weight is lower, since the tariff for the population is not so significant as the rational use of budget found. The difference between weights of the heat tariff and hot water is explained by the fact that many MUs are not provided with hot water.

TABLE 2. WeGHT VALUE OF INDICATOR

\begin{tabular}{ll}
\hline Name of indicator & Weight value \\
\hline Subsidization indicator & 0.3 \\
Efficiency of boiler capacity use & 0.3 \\
Average heat tariff & 0.25 \\
Average hot water tariff & 0.15 \\
\hline
\end{tabular}

The TOPSIS was applied to the Irkutsk region MU data (Table 1). 10 MU are ranked out and shown in Table 3. They are recommended for more detailed consideration of measures on upgrading the municipal DHS, and deciding on methods for their implementation. Along with selection of priority MU for DHS retrofitting, the priority directions for retrofitting the heat sources, heat networks and consumption systems can be chosen in future research. 
TABLE 3. INDiCATORS FOR ASSESSING THE StATE OF THE HeAt POWER INDUSTRY IN SELECTED MU OF IRKUTSK REGION

\begin{tabular}{lllll}
\hline \multirow{2}{*}{ Name of MU } & $\begin{array}{l}\text { Subsidization } \\
\text { indicator, } \\
\text { Rur/MWh }\end{array}$ & $\begin{array}{l}\text { Efficiency of boiler } \\
\text { capacity use, } \%\end{array}$ & $\begin{array}{l}\text { Average tariff, } \\
\text { Rur/MWh }\end{array}$ \\
\cline { 4 - 5 } & 523 & 73 & 1963 & 1303 \\
\hline Tulun province & 32 & 52 & 1306 & 1338 \\
Nizhneilimsk province & 2073 & 72 & 0 & 599 \\
Katangsky province & 1029 & 45 & 1179 & 1413 \\
Bodaibo MU and the area & 1706 & 77 & 618 & 892 \\
Alarsky province & 255 & 72 & 1434 & 1530 \\
Kazachinsko-Lensk province & 383 & 30 & 1069 & 1568 \\
Zima province & 509 & 46 & 0 & 1297 \\
Zhigalovo province & 428 & 44 & 0 & 1401 \\
Kachug province & 48 & 68 & 1136 & 1058 \\
Ust-Kut MU & & & & \\
\hline
\end{tabular}

\section{Conclusions}

The municipal DHS of the Irkutsk region, as well as the country as a whole, is characterized by problems associated with the unsatisfactory condition of fixed assets, the difficult economic situation in municipalities, the shortage of fuel to hard-to-reach, remote areas and, as a result, high tariffs for the population and the public sector for heat and hot water.

To select priority areas of the region for the purpose of conducting priority measures, the most significant indicators for assessing the state of municipal DHS of the MU under consideration were selected and a methodology based on the application of the TOPSIS method was proposed. The TOPSIS was applied to the Irkutsk region MU data and 10 provinces were ranked by energy efficiency and chosen for the implementation of the necessary measures to improve the state of minicipal DHSs.

\section{ACKNOWLEDGEMENT}

The research was carried out under State Assignment, Project 17.1.4 (reg. no. AAAA-A17-117030310432-9) of the Fundamental Research of Siberian Branch of the Russian Academy of Sciences.

\section{REFERENCES}

[1] Ziemele J., Gravelsins A., Blumberga A., Blumberga D. The effect of energy efficiency improvements on the development of 4th generation district heating. Energy Procedia 2016:95:522-527.

https://doi.org/10.1016/j.egypro.2016.09.079

[2] Vigants E., Prodanuks T., Vigants G., Veidenberg I., Blumberga D. Modelling of Technological Solutions 4th Generation DH Systems. Environmental and Climate Technologies 2017:20(1):5-23. https://doi.org/10.1515/rtuect-2017-0007

[3] Volkova A., Masatin V., Siirde A. Methodology for evaluating the transition process dynamics towards 4th generation district heating networks. Energy 2018:150:253-261. https://doi.org/10.1016/j.energy.2018.02.123

[4] Lund H., et al. The status of 4th generation district heating: Research and results. Energy 2018:164:147-159. https://doi.org/10.1016/j.energy.2018.08.206 
[5] Cimdina G., Timma L., Veidenbergs I., Blumberga D. Environmental and Climate Technologies Methodologies Used for Scaling-up From a Single Energy Production Unit to State Energy Sector. Environmental and Climate Technologies 2015:15(1):5-21. https://doi.org/10.1515/rtuect-2015-0002

[6] Blumberga A., Lauka D., Barisa A., Blumberga D. Modelling the Baltic power system till 2050. Energy Conversion and Management 2016:107:67-75. https://doi.org/10.1016/j.enconman.2015.09.005

[7] Pakere I., Lauka D., Blumberga D. Estimation of Carbon Emission Reduction from Upgrading the DH Network to the $4^{\text {th }}$ Generation. Multivariate Linear Regression Model. Environmental and Climate Technologies 2019:23(2):64-73. https://doi.org/10.2478/rtuect-2019-0055

[8] Polikarpova I., Lauka D., Blumberga D., Vigants E. Multi-Criteria Analysis to Select Renewable Energy Solution for District Heating System. Environmental and Climate Technologies 2019:23(3):101-109. https://doi.org/10.2478/rtuect$\underline{2019-0082}$

[9] Mednikova E., Stennikov V., Postnikov I., Penkovskii A. Development Features of Heat Power Industry Legislation in Russia. Environmental and Climate Technologies 2019:23(2):22-35. https://doi.org/10.2478/rtuect-2019-0052

[10] Nielsena B. F., Baerb D., Lindkvista C. Identifying and supporting exploratory and exploitative models of innovation in municipal urban planning; key challenges from seven Norwegian energy ambitious neighborhood pilots. Technological Forecasting \& Social Change 2019:142:142-153. https://doi.org/10.1016/j.techfore.2018.11.007

[11] Institutional pathways to municipal energy companies in the UK: Realising co-benefits to mitigate climate change in cities. Journal of Cleaner Production 2018:182:727-736. https://doi.org/10.1016/j.jclepro.2018.02.002

[12] Neves D., Baptista P., Simoes M., Silva C. A., Figueira J.R. Designing a municipal sustainable energy strategy using multi-criteria decision analysis. Journal of Cleaner Production 2018:176:251-260. https://doi.org/10.1016/j.jclepro.2017.12.114

[13] Ziemele J., Gravelsins A., Blumberga A., Blumberga D. Combining energy efficiency at source and at consumer to reach 4th generation district heating: Economic and system dynamics analysis. Energy 2017:137:595-606 https://doi.org/10.1016/j.energy.2017.04.123

[14] Ziemele J., Gravelsins A., Blumberga A., Blumberga D. Decomposition analysis of district heating system based on complemented Kaya identity. Energy Procedia 2015:75:1229-1234. https://doi.org/10.1016/j.egypro.2015.07.164

[15] Vakulenko I., Myroshnychenko I. Approaches to the Organization of the Energy Efficient Activity at the Regional Level in the Context of Limited Budget Resources during the Transformation of Energy Market Paradigm. Environmental and Climate Technologies 2015:15(1):59-76. https://doi.org/10.1515/rtuect-2015-0006

[16] Prodanuks T., Blumberga D. Methodology of municipal energy plans. Priorities for sustainability. Energy Procedia 2018:147:594-599. https://doi.org/10.1016/j.egypro.2018.07.076

[17] Kavals E., Klavnieks K., Gusca J., Blumberga D. Indicator analysis of integrated municipal waste management system. Case of study of Latvia. Energy Procedia 2018:147:227-234. https://doi.org/10.1016/j.egypro.2018.07.086

[18] Long-term targeted program "Energy-saving and enhancement of the energy performances on the territory of Irkutsk region in 2011-2015 and for the period till 2020". [Online]. [Accessed 10.11.2019]. Available: https://gisee.ru/law/programs/47135

[19] Pohekar S. D., Ramachandran M. Application of multi-criteria decision making to sustainable energy planning - A review. Renewable and Sustainable Energy Reviews 2004:8(4):365-381. https://doi.org/10.1016/j.rser.2003.12.007

[20] Løken, E. Use of multicriteria decision analysis methods for energy planning problems. Renewable and Sustainable Energy Reviews. 2007:11(7):1584-1595. https://doi.org/10.1016/j.rser.2005.11.005

[21] Wang, J. J., Jing, Y. Y., Zhang, C. F., Zhao, J. H. Review on multi-criteria decision analysis aid in sustainable energy decision-making. Renewable and Sustainable Energy Reviews 2009:13(9):2263-2278. https://doi.org/10.1016/j.rser.2009.06.021

[22] Adem Esmail B., Geneletti D. Multi-criteria decision analysis for nature conservation: A review of 20 years of applications. Methods in Ecology and Evolution 2018:9(1):42-53. https://doi.org/10.1111/2041-210X.12899

[23] Larichev O. I. Theory and decision-making methods: textbook. Moscow: Logos, 2002.

[24] Mikoni S. V. Multicriteria choice on a finite set of alternatives. St. Petersburg: Lan, 2009.

[25] Hwang C. L., Yoon K. Methods for multiple attribute decision making. In Multiple attribute decision making. Berlin, Heidelberg: Springer, 1981. https://doi.org/10.1007/978-3-642-48318-9

[26] Ishizaka A., Nemery P. Multi-Criteria Decision Analysis. Methods and Software. Chichester (United Kingdom): John Wiley \& Sons Inc, 2013. https://doi.org/10.1002/9781118644898

[27] Jahanshahloo G. R., Lotfi F. H., Izadikhah M. An algorithmic method to extend TOPSIS for decision-making problems with interval data. Applied Mathematics and Computation. 2006:175(2):1375-1384. https://doi.org/10.1016/j.amc.2005.08.048

[28] Integral assessment of social stability in municipal units of the Angara area. Analytical note. Irkutsk: Irkutskstat, 2017.

[29] Budgets of municipal units of Irkutsk region. Analytical note. Irkutsk: Irkutskstat, 2017. 